\title{
Temporomandibular joint pathosis related to sex, age, and dentition in autopsy material
}

\author{
Sven E. Widmalm, DDS, PhD, ${ }^{a}$ Per-Lennart Westesson, DDS, PhD, \\ In-Kwon Kim, DDS, MS, ${ }^{\mathrm{c}}$ Francisco J. Pereira, Jr, DDS, MS, ${ }^{\mathrm{d}}$ \\ Håkan Lundh, DDS, PhD, ${ }^{\circ}$ and Mark M. Tasaki, DDS, MS, PhD, ${ }^{f}$ \\ Ann Arbor, Mich., Rochester, N.Y., Seoul, Korea, and Malmö, Sweden \\ UNIVERSITY OF MICHIGAN SCHOOL OF DENTISTRY, UNIVERSITY OF ROCHESTER, SCHOOL OF \\ MEDICINE AND DENTISTRY, YONSEI UNIVERSITY, AND UNIVERSITY OF LUND
}

The purpose of this autopsy study was to test the hypotheses that temporomandibular joint (TM) arthrosis is more common in women than in men, increases with age, and is more common in edentulous persons than in those with natural teeth. Two hundred forty-eight TMJs removed at autopsy from 224 fresh cadavers were investigated macroscopically with dissection or cryosectioning. Age was found to be a significant factor in prediction of TM) arthrosis $(p<0.001)$ and of disk perforation $(p<0.05)$. No significant association was found between morphologic changes in the $1 \mathrm{MJ}$ and the factor of sex for the whole group. Disk displacement and disk perforation were, however, more common in the joints of women than men in the group of persons 80 years of age or older $(p<0.05)$. There were significant associations $(p<0.001)$ between arthrosis, disk displacement, disk deformation, and disk perforation. There were no statistically significant differences in the prevalence of morphologic changes in the joints from persons with 10 or more natural teeth in each jaw compared with those from persons without natural teeth. The results of this study showed that TMJ arthrosis is more frequent in older than in younger persons. TMJ disk displacement generally appears necessary for the development of perforations. The findings of this study indicate that sex and dentition are not major factors for the development of TMJ pathosis in elderly individuals. (Oral Surg Oral Med Oral PATHOL 1994;78:416-25)

This study was supported by a grant from the Torsten and Ragnar Söderberg Foundations, Stockholm, Sweden, Praktikertjänst AB, Sweden, NIH (no, RO3-DEO9133-01), and Office of the Vice President of Research, University of Michigan, Ann Arbor, Mich.

${ }^{a}$ Associate Professor, Department of Cariology, Restorative Sciences, and Endodontics, University of Michigan School of Dentistry.

"Professor of Radiology, Chief of IIcad and Neck Imaging, Department of Radiology, University of Rochester.

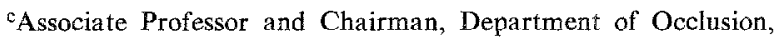
College of Dentistry, Yonsei University; Visiting Assistant Professor, University of Rochester; Visiting Assistant Professor, University of Michigan.

dPostgraduate student, Department of Stomatognathic Physiology, Centre for Oral Health Sciences, University of Lund.

${ }^{\mathrm{e} A s s o c i a t e}$ Professor, Department of Stomatognathic Physiology, Centre for Oral Health Sciences, University of Lund.

fVisiting Researcher, Department of Radiology, University of Rochester School of Medicine and Dentistry.

Copyright (0) 1994 by Mosby-Year Book, Inc.

$0030-4220 / 94 / \$ 3.00+0 \quad 7 / \mathbf{1 2} / \mathbf{5 6 7 9 8}$
Clinical studies report that women have temporomandibular joint (TMJ) disorders and come for treatment more often than men. The women to men ratio has ranged from 2.3:1 to 9:1., 2 Magnetic resonance imaging (MRI) studies have shown a high prevalence of different forms of disk displacement in patients about to be treated for TMJ pain and dysfunction. ${ }^{3}$ Over the years we have conducted multiple studies on TMJ autopsy specimens, but we have not seen a strikingly higher prevalence of morphologic changes in the joints of women compared with the joints of men. The first purpose of this investigation was to compare the prevalence of morphologic alterations in women and men.

It has been suggested in earlier studies ${ }^{4}$ that morphologic alterations increase with age. This is an important observation because the number of patients with TMJ signs and symptoms appear to decrease with age. ${ }^{5,6}$ The second purpose was to study morphologic changes in relation to age. 


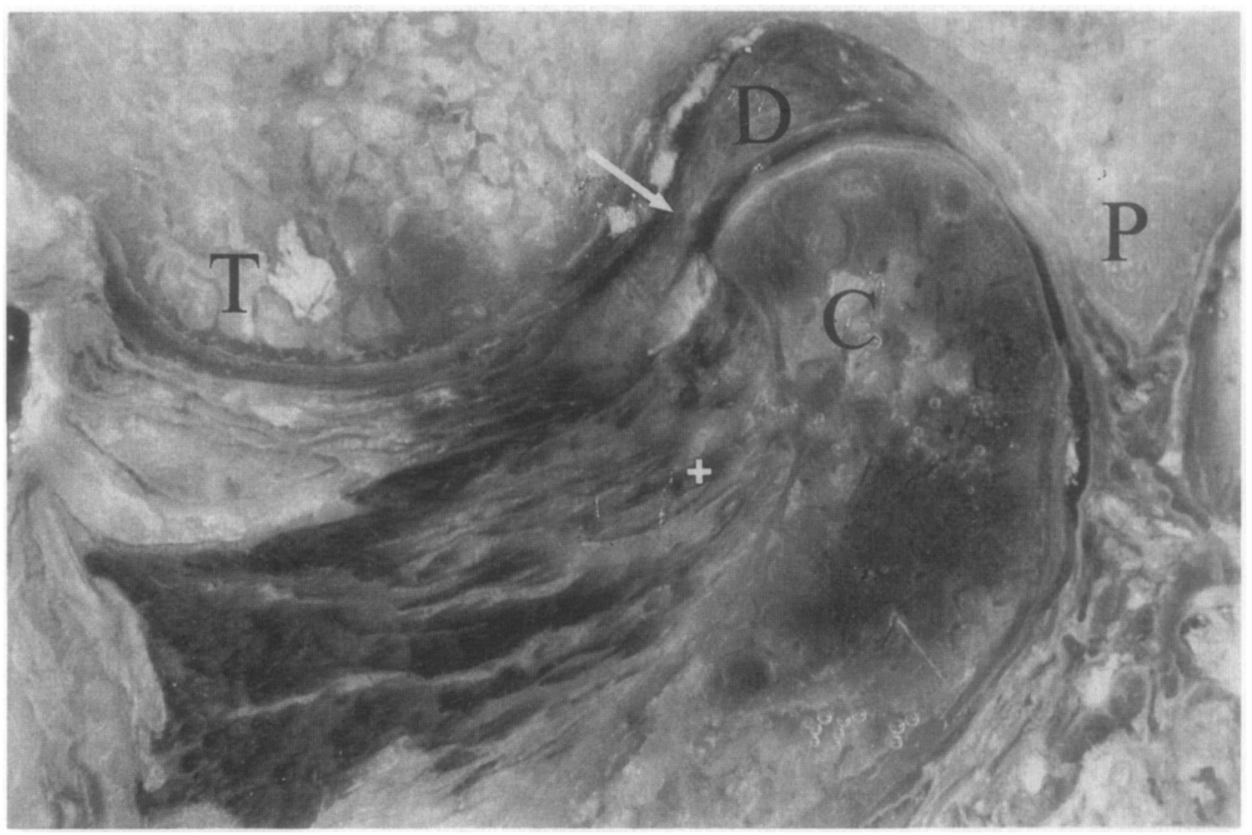

Fig. 1. Sagittal cryosection of joint with disk in normal superior position and normal articular surfaces. The condyle $(C)$ is seated in the glenoid fossa and located inferior to the posterior band of the disk $(D)$. Arrow points at the central thin part of the disk. Tubercle $(T)$, postglenoid tubercle $(P)$ and lateral pterygoid muscle $(+)$ are indicated.

Table I. Age and sex distribution

\begin{tabular}{|c|c|c|c|}
\hline & Number & Mean age & Standard deviation \\
\hline Men & 154 & 71.5 & 10.89 \\
\hline Women & 94 & 73.6 & 10.76 \\
\hline Men $<80$ years of age & 117 & 67.4 & 9.07 \\
\hline Women $<80$ years of age & 59 & 67.7 & 9.26 \\
\hline Men $>79$ years of age & 37 & 84.4 & 3.83 \\
\hline Women $>79$ years of age & 35 & 83.4 & 3.40 \\
\hline All specimens & 248 & 72.3 & 10.87 \\
\hline
\end{tabular}

The age range was 33 to 94 for the specimens from men and 43 to 92 for those from women. A $t$ test of mean ages did not show significant differences between specimens from men and women in any subgroup. Levenc's test for equality of variances did not show significant diffcrences in any subgroup.

It has been suggested that morphologic changes are associated with a lack of natural teeth, ${ }^{4,7}$ and the third purpose of the study was therefore to relate the presence of morphologic alterations in the TMJ to the presence or absence of natural teeth.

\section{MATERIAL AND METHODS}

The study was based on 248 TMJs ( 154 from men, 94 from women). The joints were removed from 224 fresh cadavers. The mean age at death was 71.5 years $(\mathrm{SD}=10.89$ years) for the men and 73.6 years $(\mathrm{SD}=10.76$ years) for the women (Table I). No information was available about TMJ symptoms before death.

Four aspects of joint morphology were evaluated: disk displacement, disk deformation, disk perforation, and arthrosis of condyle, glenoid fossa, and articular eminence. The position of the disk was classified as normal or displaced according to previously described criteria. ${ }^{8}$ Normal position was denoted when the posterior band of the disk was superior to the condyle and the central thin zone of the disk was located between the anterior prominence of the condyle and the posterior prominence of the articular eminence (Fig. 1). A displaced disk was denoted when the disk was displaced from the superior position (Fig. 2). The form of the disk was classified as normal biconcave or as deformed. Deformation included thickening of the posterior band, biplanar, or biconvex configuration of the disk. Perforation was denoted when there was communication between the lower and upper joint spaces (Figs. 3 and 4). Perforations were seen most 


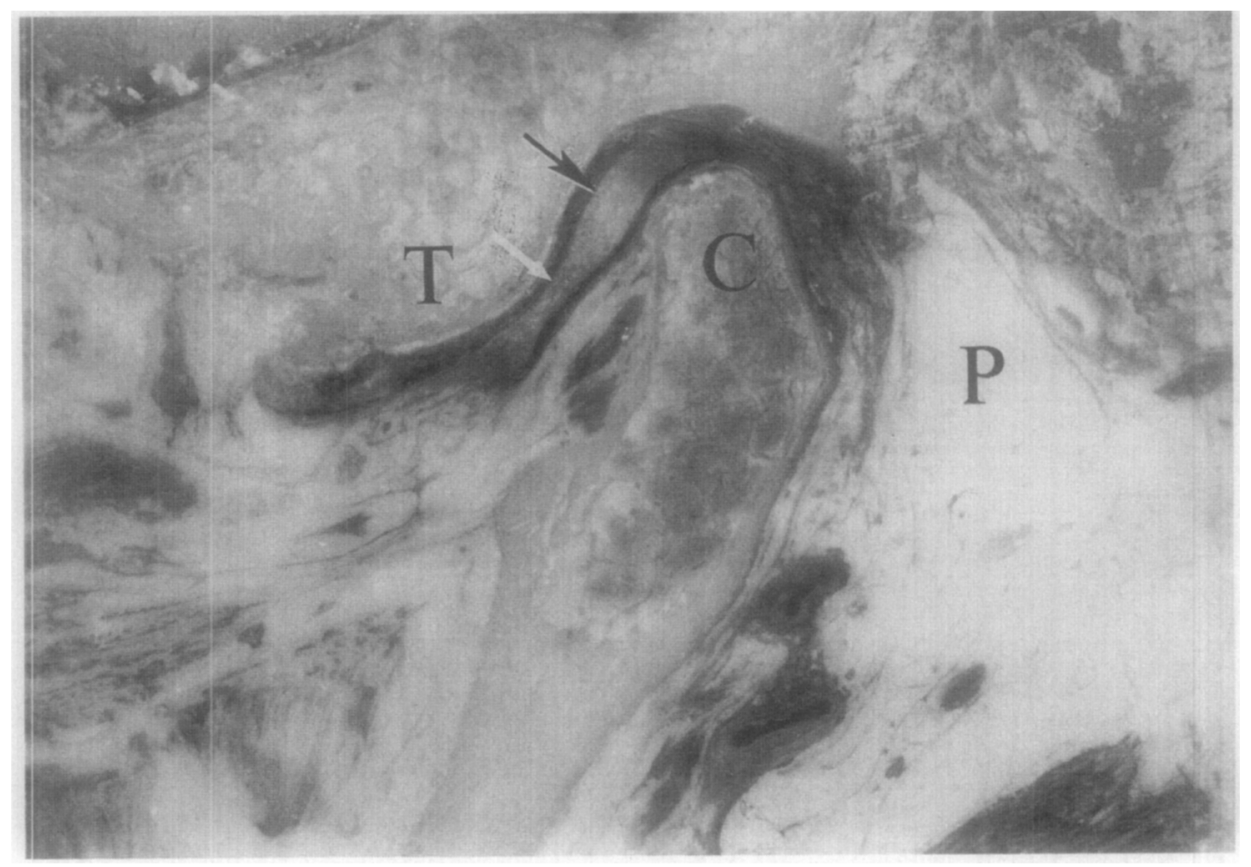

Fig. 2. Sagittal cryosection shows disk with normal surfaces displaced anterior to condyle. Posterior band (black arrow), central thin part (white arrow), tubercle $(T)$ and parotid gland $(P)$ are indicated.

Table II. Prevalence of morphologic changes (all specimens $\mathrm{N}=248$ )

\begin{tabular}{l|c|c|c}
\hline & $\begin{array}{c}\text { Men (\%) } \\
N=154\end{array}$ & $\begin{array}{c}\text { Women (\%) } \\
N=94\end{array}$ & $\mathrm{p}$ \\
\hline Disk displaced & 53.9 & 63.8 & 0.125 \\
Disk deformed & 33.3 & 42.6 & 0.145 \\
Disk perforated & 10.4 & 19.1 & 0.052 \\
Arthrosis & 18.8 & 25.5 & 0.212 \\
\hline
\end{tabular}

$p=$ probability value for difference between men and women. $p$-values $<0.30$ indicate that the variable should be included when testing a logistic regression model (see Table VII).

frequently in the posterior disk attachment but occasionally also in the disk proper. Arthrosis of the articular surfaces was noted when the smooth, shiny articular surface was replaced by irregularities and exposure of bone (Figs. 4 and 5).

Cryosectioning or dissection was used to assess joint morphology and performed as previously descrihed.$^{9}$ At the time of autopsy the remaining natural teeth were counted. Fixed crowns and bridge pontics were included in the number of remaining teeth. Artificial teeth in removable dentures were not included in the count of remaining teeth.

Differences between observed and expected frequencies were tested using Yates corrected $\chi^{2}$ test as default and Fisher's exact test when expected frequency was less than five in any cell. Tests of statistical significance do not measure the strength of rela- tionship between variables; they only show if a relationship exists. To measure the strength of one association we used Cramér's $V$ test that is a $\chi^{2}$-based measure of association that can attain values between 0 and 1 for tables of any dimension. Zero corresponds to no association and 1 to perfect association. The values were calculated using the formula:

$$
\mathrm{V}=\sqrt{\chi^{2} / \mathrm{N}(\mathrm{k}-1)}
$$

where $k$ is the smaller of the number of rows and columns, $N=$ number of observations and $\chi^{2}=$ the Pearson chi-square statistic. The association was to be considered negligible if Cramér's $V$ was less than 0.10 ; weak if equal to or higher than 0.10 but below 0.20 ; moderate if equal to or higher than 0.20 but below 0.40 ; relatively strong if equal to or higher than 0.40 but below 0.60 ; strong if equal to or higher than 0.60 but below 0.80 ; and very strong if equal to or above 0.80 . None of the values in this study were greater than 0.60 . Cramér's $V$ rarely achieves a value of 0.80 or above. ${ }^{10,11}$

The age distributions in the different subgroups were compared using the Levene test for evaluating the assumption that the groups came from populations with equal variances. ${ }^{12}$ The null hypothesis that group variances were equal was rejected if $p>0.05$. The Independent-Samples $T$ test procedure was used to compute Student's $t$ statistic for testing the significance of a difference in age-means for independent 


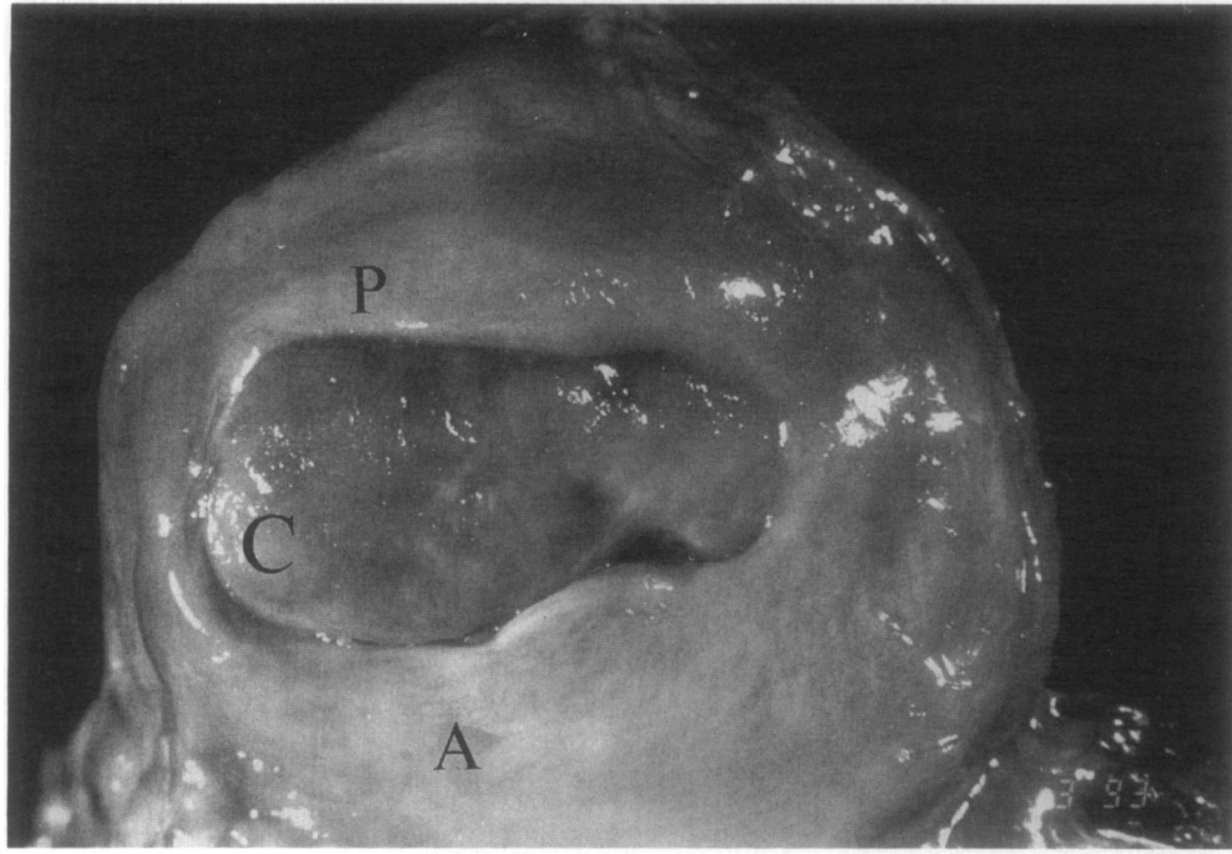

Fig. 3. Anterior superior view of disk with large perforation and condyle $(C)$ with arthrotic changes as seen in dissection. The anteriorly displaced disk $(A)$ and the posterior disk attachment $(P)$ are indicated.

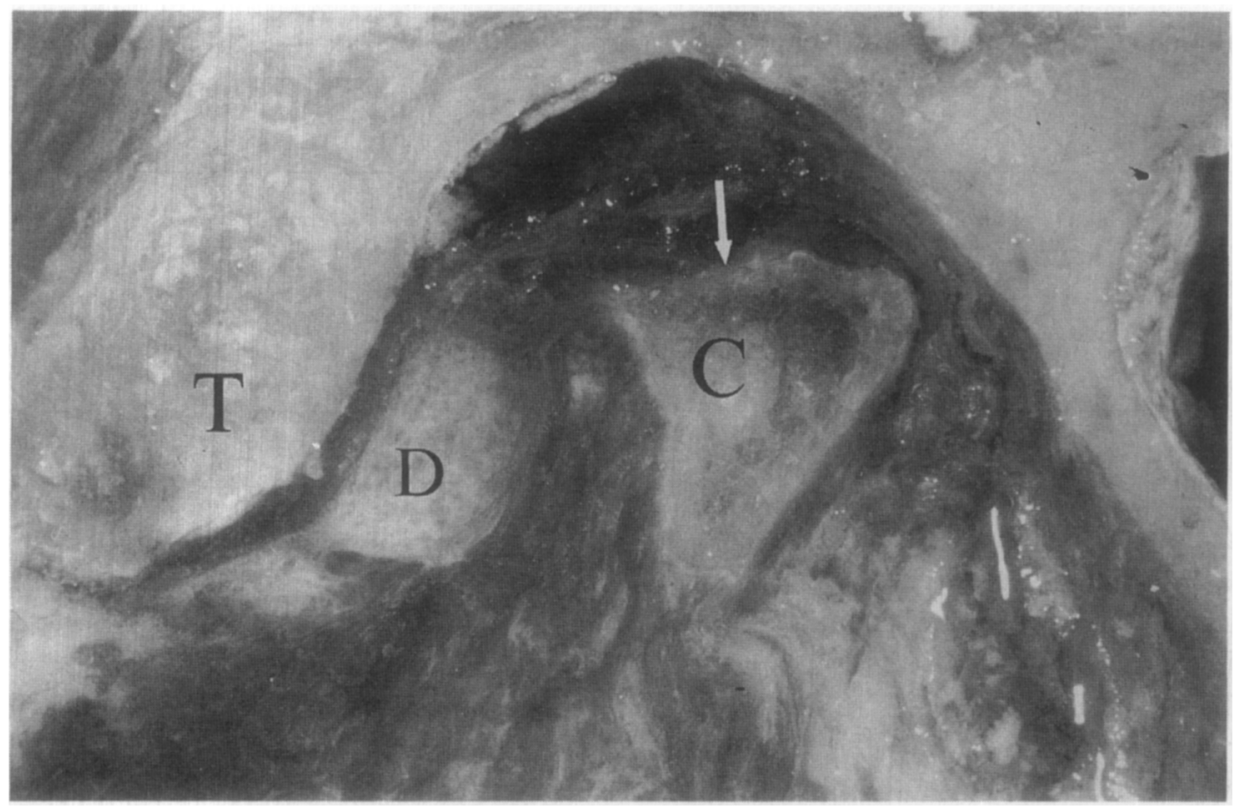

Fig. 4. Sagittal cryosection shows anteriorly displaced and perforated disk (D) with severe arthrosis (arrow) both of condyle $(C)$ and of temporal component $(T)$.

samples. ${ }^{12}$ Logistic regression was used to estimate the effect of age, sex, and dentition on the morphologic variables. ${ }^{13}$

The relationship between morphologic alterations in the joint and dentition was analyzed by dividing the TMJs into two groups. One group was composed of those from persons with at least 10 remaining teeth in both the upper and the lower jaws, a total of 20 or more teeth. The other group contained TMJs from those persons who were edentulous, that is, they had no remaining natural teeth. Edentulous persons, both with and without dentures, were included in this lat- 


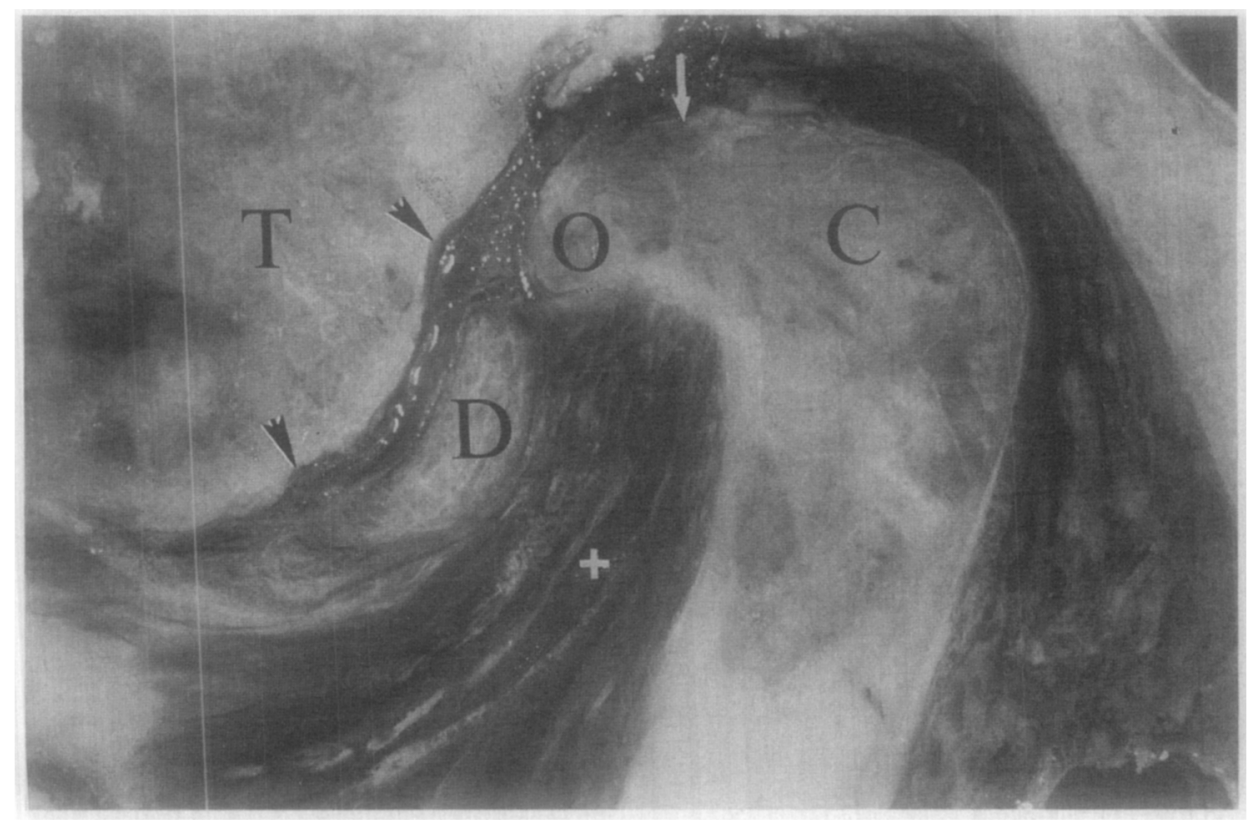

Fig. 5. Sagittal cryosection shows large disk perforation (arrow) and arthrotic changes with exposure of bone on condyle $(C)$ and in glenoid fossa indicated by arrowheads. Osteophyte anteriorly $(O)$ on the condyle, a portion of the anteriorly displaced disk $(D)$, the tubercle $(T)$, and the lateral pterygoid muscle $(+)$, are indicated.

Table III. Prevalence of morphologic TMJ changes in various age groups. $\mathrm{N}=248$.

\begin{tabular}{l|c|c|c}
\multicolumn{1}{c|}{ Age group } & $\begin{array}{c}<64 \text { years } \\
\mathrm{n}=56\end{array}$ & $\begin{array}{c}65 \text { to } 79 \text { years } \\
\mathrm{n}=120\end{array}$ & $\begin{array}{c}>80 \\
\mathrm{n}=72\end{array}$ \\
\hline Age & & & 83.9 years \pm 3.63 \\
Mean $\pm \mathrm{SD}$ & 56.7 years \pm 7.05 & 72.6 years \pm 4.18 & $62.5 \%$ \\
Disk displaced & $51.8 \%$ & $57.5 \%$ & $41.7 \%$ \\
Disk deformed & $26.8 \%$ & $38.7 \%$ & $23.6 \%$ \\
Disk perforated & $5.4 \%$ & $11.7 \%$ & $34.7 \%$ \\
Arthrosis & $8.9 \%$ & $19.2 \%$ & \\
\hline
\end{tabular}

ter group. Thus two extreme groups were used for analysis of the influence of dentition. TMJs from 85 persons, who did not fit into either of these groups, were excluded from this analysis. The term dentition was used to characterize this analysis in the presentation of the results and in the discussion. The mean age of those with 20 or more remaining teeth was lower $(p<0.001)(65.4$ years $\pm 12.50 \mathrm{SD}, \mathrm{N}=60)$ than those without teeth $(76.8$ years $\pm 8.61 \mathrm{SD}$, $\mathrm{N}=103$ ). Comparison between the groups was therefore made with logistic regression instead of the $\chi^{2}$ test to avoid the confounding effect of differences in age.

\section{RESULTS}

The prevalence of displaced, deformed, and perforated disks was higher, but not significantly higher, in the TMJs of women than in those of men (Table II). The prevalence of morphologic changes increased with age (Table III), but the age factor as tested by logistic regression was significant only in the prediction of arthrosis and disk perforation (Table IV). No sex differences were obscrved in those under 80 years of age (Table V). In those who were 80 years and older (Table VI), however, there was a significantly higher prevalence of disk displacement and disk perforation in TMJs from women than men $(p<0.05)$.

In 24 persons both left and right TMJs were removed. The morphologic alterations were similar on both sides in 14 of those persons. Seven persons had differences between sides with respect to one variable, and three persons had differences with respect to two variables.

No significant difference in prevalence of any of the 
Table IV. Evaluation of age and sex factors using a logistic regression model. $\mathrm{N}=248$.

\begin{tabular}{l|c|c|c|c}
\hline & $\begin{array}{c}\text { Overall correctness } \\
(\%)\end{array}$ & Age & $\begin{array}{c}\text { Model } \\
\text { p-value }\end{array}$ \\
\hline Disk displaced & 58.9 & NS & NS & 0.280 \\
Disk deformed & 63.2 & NS & NS & 0.214 \\
Disk perforated & 86.3 & $p<0.05$ & $p \sim 0.055$ & 0.001 \\
Arthrosis & 79.4 & $p<0.001$ & NS & 0.001 \\
\hline
\end{tabular}

$p$ - probability value for column variable.

NS = column variable not significant.

Table V. Prevalence of morphologic changes in specimens from persons $<80$ years of age $\mathrm{N}=176$.

\begin{tabular}{l|c|c|c}
\hline & $\begin{array}{c}\text { Men } \\
N=I 17\end{array}$ & $\begin{array}{c}\text { Women } \\
N=59\end{array}$ & $\mathrm{p}$ \\
\hline Disk displaced & $54.7 \%$ & $57.6 \%$ & 0.712 \\
Disk deformed & $32.8 \%$ & $39.0 \%$ & 0.414 \\
Disk perforated & $9.4 \%$ & $10.2 \%$ & 0.871 \\
Arthrosis & $17.1 \%$ & $13.6 \%$ & 0.545 \\
\hline
\end{tabular}

$p=$ probability value for difference between nuen and women.

recorded morphologic changes in the TMJ were observed when the disks from persons with natural dentition (detined as 10 or more teeth in each jaw) were compared with those from edentulous persons. The prevalence values for edentulous/dentulous were for disk displacement $61.2 \% / 55.0 \%(p \sim 0.440)$, deformed disk $39.8 \% / 30.5 \%(p \sim 0.237)$, arthrosis $21.4 \% / 10.0 \%(p \sim 0.064)$, and for disk perforation $15.5 \% / 8.3 \%(p \sim 0.186)$.

Logistic regression models were obtained with good overall correctness, using the factors age and sex for prediction of disk perforation (correctness $86.3 \%$ ) and arthrosis (correctness $79.4 \%$ ) (Table IV). Age was a significant factor in both predicting disk perforation $(p<0.05)$ and arthrosis $(p<0.001)$. The sex factor had a low $p$-value $(p \sim 0.055)$ in prediction of disk perforation. This model was also improved by adding the interaction age/sex factor. The models for disk displacement and disk deformation could not be significantly improved by adding age and sex factors. No model gained by adding the dentition factor. There were significant associations between all the recorded morphologic variables, disk displacement, arthrosis, disk deformation, and disk perforation $(p<0.001)$ (Table VII).

\section{DISCUSSION}

The most important result of this study was that the prevalence of morphologic changes were similar in $T M J_{s}$ from men and women under 80 years of age (Table V). This result disagrees with the well-known
Table V. Prevalence of morphologic changes in specimens from persons $\geq 80$ years of age $N=72$.

\begin{tabular}{l|c|c|c}
\hline & $\begin{array}{c}\text { Men (\%) } \\
N=37\end{array}$ & $\begin{array}{c}\text { Women (\%) } \\
N=35\end{array}$ & $\mathrm{p}$ \\
\hline Disk displaced & 51.4 & 74.3 & 0.045 \\
Disk deformed & 35.1 & 48.6 & 0.248 \\
Disk perforated & 13.5 & 34.3 & 0.038 \\
Arthrosis & 24.3 & 45.7 & 0.057 \\
\hline
\end{tabular}

$p=$ probability value for difference between men and women.

clinical finding that the female/male ratio in patients who seek treatment for TMJ pain and dysfunction is heavily biased to the woman side. Another result of interest was the increase of morphologic changes with age, which is in contrast to the decrease in treatment need reported by several epidemiologic studies. ${ }^{5,6,14}$ Taken together those two discrepancies between the presence of gross morphologic changes in autopsy material and treatment need in living patients indicate that the relationship between arthrotic changes, internal derangement, and pain/dysfunction is complicated and far from linear. That is, the presence of morphologic changes in the joint may or may not be associated with clinical symptoms. Patient diagnosis and treatment planning should therefore be based on both clinical examination findings and imaging evidence of morphologic alterations in the joint. As has been pointed out in earlier studies, ${ }^{15}$ it does not seem justified to treat asymptomatic persons with morphologic alterations of the joint.

Musculoskeletal abnormalities in asymptomatic persons are not unique to the TMJ. A prospective and blinded MRI investigation ${ }^{16}$ of the knee in asymptomatic volunteers has shown $16 \%$ meniscal abnormalities consistent with a tear. The same study observed a $13 \%$ incidence of abnormality in those persons younger than 45 years of age whereas the abnormalities were seen in $36 \%$ of those older than 45 , which suggests an increasing frequency of asymptomatic meniscal abnormalities with increasing age. ${ }^{17}$ Concerning the lumbar disk, multiple studies have 
Table VII. Association between variables. $\mathrm{N}=248$.

\begin{tabular}{l|c|c|c}
\hline & $\begin{array}{c}\text { Disk } \\
\text { displaced }\end{array}$ & $\begin{array}{c}\text { Disk } \\
\text { deformed }\end{array}$ & $\begin{array}{c}\text { Disk } \\
\text { perforated }\end{array}$ \\
\hline Disk deformed & 0.55 & - & \\
Disk perforated & 0.34 & 0.45 & - \\
Arthrosis & 0.37 & 0.53 & 0.45 \\
\hline
\end{tabular}

Values of Cramér's $V$ are given. All associations were significant $(p<0.001)$ Cramér's $V: 0.20$ to $0.40=$ moderate association. 0.40 to $0.60=$ relatively strong association.

demonstrated abnormalities in the general population. ${ }^{18-23}$ Thus a recent MRI study showed abnormal lumbosacral intervertebral disks in more than $40 \%$ of asymptomatic women. ${ }^{22}$ Also the cervical spine has demonstrated abnormality in about $19 \%$ of asymptomatic subjects. ${ }^{16}$ The relationship between MRI findings of disk abnormalities and clinical symptoms were also discussed with respect to the lumbosacral spine. $^{23}$

\section{Prevalence of morphologic changes}

The effect of age, sex, and loss of teeth on TMJ morphology are difficult to separate in autopsy studies. This study clearly showed, however, that age is a significant factor with respect to arthrosis and disk perforation. The increase of morphologic alterations observed in older persons is in accordance with earlier studies on both TMJ disorders ${ }^{4}$ and other musculoskeletal disorders. ${ }^{24}$

This study showed a similar prevalence of disk displacement, disk deformation, and arthrotic changes in the joints of women and of men. This is certainly different from the patient population in which clinicians see a significantly higher number of women than men. ${ }^{1,2}$ The probability values, however, were all below 0.30 , which indicates that those variables should be considered in logistic regression models. ${ }^{13}$

There was also a slightly higher prevalence of disk displacement and perforation in the TMJs of women than men in the group over 79 ( 80 or more) years of age $(p<0.05)$. The difference in distribution of disk pcrforations, found in this study, supports the view that in older persons the TMJ disk in the woman is more vulnerable than that in the man. ${ }^{25,26}$ It has been suggested that this may be due to inherent sex differences in articular cartilage. ${ }^{27}$ The findings motivate further autopsy studies with histologic examination of younger specimens to see if earlier stages of disk alterations that may eventually progress to perforations are more common in women than in men in those age groups when treatment need is at a peak. This is a macroscopic study with limitation to gross changes. Repeated examinations on larger groups of specimens are needed before definite conclusions about possible differences on the basis of sex can be drawn. Differences may also be more truthfully interpreted if the variables are graded according to degree, severity, etc. ${ }^{4,26}$ This means that further studies should preferably include dissection and histologic preparations, which are most valuable for more detailed classifications.

\section{The effect of internal derangement}

There are few studies on the epidemiology of internal derangement. A recent epidemiologic study ${ }^{28}$ that investigated 402 persons selected to represent the general population did not find any significant differcnecs between men and women with respect to symptoms of internal derangement. These observations sharply contradict the common finding of a much higher prevalence of women patients among those seeking treatment for symptoms related to TMJ disorders. In multiple studies the women to men ratio ranges from $2.3: 1$ to $9: 1,1,2$

The correlation between findings of disk deformation, disk displacement, and degenerative joint disease on one hand and symptoms such as pain and dystunction on the other hand is not clear. It is obvious from studies of asymptomatic volunteers that many persons can have asymptomatic disk displacement. ${ }^{3,29,30}$ On the other hand a recent study found the prevalence of different forms of internal derangement in symptomatic TMJ patients to be close to $80 \%,{ }^{3}$ It is our experience that internal derangement per se does not always cause clinical symptoms. Internal derangement is certainly a contributing factor, but inflammatory changes in the joint capsule, synovial tissues, and retrodiskal tissues are probably more important for the development of symptoms than disk displacement or deformation per se.

Synovial effusion may occur from inflammatory, degenerative, or mechanical causes. ${ }^{31}$ A recent MRI study, ${ }^{32}$ has shown that joint effusion is more closely associated to pain than disk displacement. It is therefore likely that imaging data indicating joint effusion, which is a sign of an inflammatory reaction, are significant in MRI diagnosis together with documentation of disk displacement. Inflammation and effusion are, however, mostly transient phenomena, indicating acute, active phases of the disease, whereas perforations, arthrotic changes, and displacements are more permanent results that may be identified in autopsy studies long after the acute flare-ups have ceased to occur. This, of course, limits the possibility of correlating autopsy findings in specimens from the elderly to the prevalence of TMJ pain in younger populations. $\Lambda$ more expanded discussion about the implications 
on pain by morphologic TMJ changes is beyond the scope of this article. The readers are referred to an excellent monograph by Johansson-Garnier. ${ }^{33}$

\section{The effect of loss of teeth}

It has been suggested in the literature that loss of all teeth may play a role in the cause of TMJ disease. ${ }^{4,7}$ In this study, joints from those persons who died with 10 or more teeth in each jaw were compared with joints from edentulous persons with or without dentures with no appreciable difference found in the status of the joints in these two categories. These were relatively extreme groups of persons and, if no appreciable difference could be noted at the end of life with these relatively marked criteria, it is unlikely that more subtle criteria at an earlier time of life should have a significant influence on the morphologic status of the joint. It seems reasonable from a mechanical point of view that loss of teeth should affect TMJ morphology in a negative way, but this has not been documented in any large systematic study. Studies with a large number of specimens, carefully matched in age, sex, and status of dentition are needed to assess the effects of those variables on TMJ abnormalities.

\section{Association between various types of morphologic changes}

There was significant association between all recorded morphologic variables $(p<0.001)$ supporting findings in earlier studies. ${ }^{9}$ For instance, all perforated disks were also displaced, but $76.2 \%$ of the displaced disks were not perforated. The association between disk displacement and disk perforation indicates that disk displacement, most of the time, is a necessary prerequisite for progress to disk perforation, but displacement alone may not be sufficient to cause perforation.

\section{Possible clinical use of regression models}

It was shown in this study that factors of age and sex can be used to create logistic regression models with good accuracy to calculate the probability that a subject has or has not had a specific pathologic change. Such models have a great potential for use as diagnostic aids and for identification of risk groups in artificial intelligence applications when combined with other information about clinical signs and symptoms. This should be helpful, for instance, when making priority lists for examinations that involve invasive or expensive procedures.

$P$-values have been given for several comparisons even if they were not significant. One reason is that $p$-valucs above 0.05 but below 0.30 are considered of interest when planning for tests with logistic regression. Another reason is that we consider it to be of interest to know if the $p$-values were or were not close to significance. The difference between $p \sim 0.045$ and $p \sim 0.057$ (for instance, see Table VI) is not large. The significance value may be by chance and the nonsignificant value may be lower in a repeated study. Low $p$-values indicate that the variables may be worth further studies in similar groups.

\section{Reliability of methods used}

In this autopsy study, we used cryosectioning and dissections of the TMJ. Cryosectioning is accurate for studying joint morphology ${ }^{34,35}$ and for tissue identification even if a more detailed image analysis without risk of tissue deformation is possible only with MRI ${ }^{8}$ With multiplanar MRI an unlimited number of axial, coronal, and sagittal images can be obtained of the same specimens with an almost $95 \%$ accuracy for disk position and degenerative joint disease. ${ }^{8} \mathrm{~A}$ limitation of cryosectioning is that a limited number of coronal and sagittal sections can be studied. The best method for observing disk perforation is probably dissection. Other macroscopic degenerative changes are also better studied by dissection than by other methods.

\section{The validity of autopsy studies}

Autopsy studies seldom have access to reliable accounts of the deceased's history of TMJ pain and dysfunction. Many dental patients do not have a complete TMJ examination. Dental records are seldom kept organized and accessible in a way that autopsy findings can be correlated to a history of TMJ pain and to other signs of temporomandibular disorders that may have occurred decades before death. Furthermore, facial pain in the area surrounding the TMJ is often the primary reason for patients to seek treatment for temporomandibular disorder, but it is a poor measure of morphologic or pathologic changes. Pain occurs, for instance, often in connection with stages when no objective signs are detectable with MRI or other advanced diagnostic methods, whereas the final stages with totally destroyed disks may be asymptomatic..$^{36-38}$ Early painful stages may have initiated a process that decades later resulted in severe but asymptomatic internal derangement. ${ }^{36,37}$ Morphologic changes have been looked on as the result of normal aging processes or signs of past disease processes $^{39}$ that may or may not have been combined with pain or dysfunction. In spite of these shortcomings, autopsy studies are valuable and necessary when relating morphologic changes to the factors of age and sex, especially to detect changes only observable in 
histology preparations. Unfortunately because of the multifactorial nature of TMJ disorders the number of specimens has to be very high to allow an appropriate statistical treatment because the number of specimens has to be in relation to the number of variables. Autopsy studies are needed to obtain reliable descriptions of the natural progress of morphologic TMJ changes from infancy to old age. Reliable information about the distribution, prevalence, and incidence of normal and abnormal changes and the effect of age and sex can then be used to compare with epidemiologic data about prevalence and incidence of clinical signs of TMJ disorders in living subjects matched in age, sex, and status of dentition.

The search for differences in morphologic changes that may explain the sex differences in treatment need is complicated by difficulty in isolating and separating the effects of sex from the effects of age, occlusion, and loss of teeth. The large number of factors with similar effects on the TMJ structures make it necessary to have a very large number of specimens, most probably much higher than most studies have had so far. Taking the need for large samples into consideration, it may be concluded that differences with respect to morphologic alterations in the joints, between men and women, and the effect of age and loss of teeth have still not been systematically documented in studies on TMJ autopsy specimens.

\section{SUMMARY}

Disk displacement, perforation, disk deformation, and arthrosis seem to increase with age. Gender and loss of teeth do not seem to have an influence on the amount of morphologic changes in the TMJ at the end of life.

\section{REFERENCES}

1. Helkimo M. Epidemiological surveys of dysfunction of the masticatory system. In: Zarb GA, Carisson GE, eds. Temporomandibular joint: function and dysfunction. Copenhagen: Munksgaard, 1979:175-92.

2. Solberg WK. Epidemiology, incidence, and prevalence of temporomandibular disorders: a review. In: Laskin D, Greenfield W, Gale E, Rugh J, Neff P, Alling C, Ayer WA, eds. The President's Conference on the Examination, Diagnosis and Management of Temporomandibular Disorders. Chicago: American Dental Association 1982;30-9.

3. Paesani D, Westesson PL, Hatala M, Tallents RH, Kurita K. Prevalence of internal derangement in patients with craniomandibular disorders. Am $J$ Orthod Dentofacial Orthop 1992;101:41-7.

4. Öberg T, Carlsson GE, Fajers CM. The temporomandibular joint: a morphological study on a human autopsy material. Acta Odontol Scand 1971;29:349-84.

5. Österberg T, Carlsson GE, Wedel A, Johansson U. A crosssectional and longitudinal study of craniomandibular dysfunction in an elderly population. J Craniomandib Disord 1992; $6: 237-45$.

6. Koidis PT, Zarifi A, Grigoriadou E, Garefis P. Effect of age and sex on craniomandibular disorders. $J$ Prosthet Dent 1993;69:93-101.

7. Axelsson S, Fitins D, Hellsing G, Holmlund A. Arthrotic changes and deviation in form of the temporomandibular joint: an autopsy study. Swed Dent J 1987;11:195-200.

8. Tasaki M, Westesson PL. MR imaging of the temporomandibular joint: diagnostic accuracy with sagittal and coronal images. Radiology 1993;186:723-9.

9. Westesson PL, Bronstein SL, Liedberg JL. Internal derangement of the temporomandibular joint: morphologic description with correlation to joint function. ORAL SURG ORAL MED Oral Pathol 1985;59:323-31.

10. Rea LM, Parker RA. Designing and conducting survey research. San Francisco: Jossey-Bass, 1992:202-4.

11. Poister TH. Public program analysis. Baltimore: University Park Press, 1978:443.

12. Norusis MJ. SPSS ${ }^{\circledR}$ for Windows ${ }^{\circledR}$ Base system user's guide. Release 6.0. Chicago: SPSS, 1992:221-6, 254-63.

13. Norusis MJ. SPSS/PC+Advanced statistics 9.0 for the IBM $\mathrm{PC} / \mathrm{XI} / \mathrm{AT}$ and PS/2. Chicago: SPSS, 1990:B39-61, C1928.

14. Widmalm SE, Christiansen RL, Gunn SM, Hawley LM, Ralph SW, Park J. Headache and TMJ pain history: age and sex-differences. J Dent Res 1993;72:338.

15. Ramfjord S, Ash MM Jr. Occlusion. Philadelphia: WB Saunders, 1983:250.

16. Boden SD, McCowin PR, Davis DO, Dina TS, Marks AS, Wiesel S. Abnormal magnetic-resonance scans of the cervical spine in asymptomatic subjects: a prospective investigation. $\mathrm{J}$ Bone Joint Surg Am 1990;72:1178-84.

17. Boden SD, Davis DO, Dina TS, et al. A prospective and blinded investigation of magnetic resonance imaging of the knee: abnormal findings in asymptomatic subjects. Clin Orthop 1992;282:177-85.

18. Modic MT, Pavlicek W, Weinstein MA, et al. Magnetic resonance imaging of intervertebral disk disease: clinical and pulse sequence considerations. Radiology 1984;152:103-11.

19. Gibson MJ, Buckley J, Mawhinney R, Mulholland RC, Worthington BS. Magnetic resonance and discography in the diagnosis of disc degeneration: a comparative study of 50 discs. J Bone Joint Surg Br 1986;68:369-73.

20. Powell MC, Wilson M, Szypryt P, Symonds EM, Worthington BS. Prevalence of lumbar disk degeneration observed by magnetic resonance in symptomless women. Lancet 1986; 2:1366-7.

21. Evans W, Jobe W, Seibert C. A cross-sectional prevalence study of lumbar disk degeneration in a working population. Spine 1989;14:60-4.

22. Weinreb JC, Wolbarsht LB, Cohen JM, Brown CE, Maravilla KR. Prevalence of lumbosacral intervertebral disk abnormalities on MR images in pregnant and asymptomatic nonpregnant women. Radiology 1989;170:125-8.

23. Horton WC, Daftari TK. Which disk as visualized by magnetic resonance imaging is actually a source of pain? A correlation between magnetic resonance imaging and discography. Spine 1992;(Suppl)17:S164-S171.

21. Adams JC. Outline of orthopaedics. Edinburgh: E \& S Livingstone LTD, 1969:51.

25. Bjelle A. Epidemiological aspects of osteoarthritis: an interview survey of the Swedish population and a review of previous studies. Scand J Rheumatol 1980;(Suppl) 43.

26. Akerman S. Morphologic, radiologic, and thermometric assessment of degenerative and inflammatory temporomandibular disease. Malmö, Sweden: University of Lund; 1987.

27. Freeman MAR, Meachim G. Aging and degeneration. In: Freeman MAR, editor. Adult articular cartilage. London: Pitman, 1979:487-543.

28. Lundh $\mathrm{H}$, Westesson PL. Clinical signs of internal derangement in adults: an epidemiological study. ORAL SURG ORAL MED ORAL PATHol 1991;72:637-41.

29. Westesson PL, Eriksson L, Kurita K. Reliability of a negative clinical temporomandibular joint examination: prevalence of 
disk displacement in asymptomatic temporomandibular joints. Oral Surg Oral Med Oral Pathol 1989;68:551-4.

30. Kircos LT, Ortendahl DA, Mark AS, Arakava M. Magnetic resonance imaging of the TMJ disk in asymptomatic volunteers. J Oral Maxillofac Surg 1987;45:852-4.

31. Moll JMH. Manual of rheumatology. Edinburgh; Churchill Livingstone, 1987:10.

32. Westesson PL, Brooks SL. Temporomandibular joint: relation between MR evidence of effusion and the presence of pain and disk displacement. Am J Roentgenol 1992;159:559-63.

33. Johansson-Garnier, AS. Temporomandibular joint internal derangement: tissue reactions and topographical relations with implication on pain. Huddinge, Sweden: School of Dentistry, Karolinska Institutet; 1990. Thesis.

34. Westesson PL, Katzberg RW, Tallents RH, Sanchez-Woodworth RE, Svensson SA, Espeland MA. Temporomandibular joint: comparison of MR inages with cryosectional anatomy. Radiology 1987;164:59-64.
35. Westesson PL, Katzberg RW, Tallents RH, Sanchez-Woodworth RE, Svensson SA. CT and MRI of the temporomandibular joint: comparison with autopsy specimens. Am J Roentgenol 1987;148:1165-71.

36. Blackwood HJJ. Arthritis of the mandibular joint. Br Dent J 1963;115:317-26.

37. Blackwood HJJ. Pathology of the mandibular joint. J Am Dent Assoc 1969;79:118-24.

38. Mayne JG, Hatch GS. Arthritis of the temporomandibular joint. J Am Dent Assoc 1969;79:125-30.

39. Stegenga B, de Bont LGM, Boering G, van Willigen JD. Tissue responses to degenerative changes in the temporomandibular joint: a review. J Oral Maxillofac Surg 1991;49:1079-88.

Reprint requests:

Sven E. Widmalm, DDS, PhD

1565 Kuehnle

Ann Arbor, MI 48103

\section{BOUND VOLUMES AVAILABLE TO SUBSCRIBERS}

Bound volumes of ORal SURgery, Oral MEDicine, AND ORAL PATHOLOGY are available to subscribers (only) for the 1994 issues from the Publisher, at a cost of $\$ 60.00$ for domestic, $\$ 76.20$ for Canadian, and $\$ 72.00$ for international, for Vol. 77 (January-June) and Vol. 78 (July-December). Shipping charges are included. Each bound volume contains a subject and author index and all advertising is removed. Copies are shipped within 60 days after publication of the last issue in the volume. The binding is durable buckram with the journal name, volume number, and year stamped in gold on the spine. Payment must accompany all orders. Contact Mosby Year Book, Subscription Services, 11830 Westline Industrial Drive, St. Louis, MO 63146-3318, USA; phone (800)453-4351, or (314)453-4351. Subseriptions must be in force to qualify. Bound volumes are not available in place of a regular journal subscription. 